\title{
Effects of argon (green) laser treatment of soft drusen in early age-related maculopathy: a 6 month prospective study
}

Department of Ophthalmology, University of Linkoping, Linkoping, Sweden

I C Frennesson

S E G Nilsson

Correspondence to: Christina Frennesson, Department of Ophthalmology, University of Linköping, S-581 85 Linköping, Sweden.

Accepted for publication 27 June 1995

\author{
I Christina Frennesson, Sven Erik G Nilsson
}

\begin{abstract}
Aim-To evaluate whether perifoveal laser photocoagulation of soft drusen reduces the total area occupied by drusen. Method-In a prospective, randomised study, 20 patients (mean age 71.3 (SD 7.7) years) with early age-related maculopathy (ARM) in the form of soft drusen and pigmentary changes and with good visual acuity $(0.94(0.09))$ were treated with argon green laser photocoagulation. Mild laser burns $(200 \mu \mathrm{m})$ were placed within a temporal horseshoe-shaped area, extending from a distance of no less than $500 \mu \mathrm{m}$ from the centre of the fovea to the vascular arcades. They were placed on the drusen and scattered over areas where no drusen were present. Fundus colour photography and fluorescein angiography were performed at study entry as well as after 3 and 6 months. Nineteen agematched patients (68.5 (6.2) years) with soft drusen maculopathy (visual acuity $0.95(0 \cdot 10)$ ) were followed as a control group. Using a computer system, the area occupied by drusen was determined as a portion of the total area of a circle with a radius corresponding to $1250 \mu \mathrm{m}$ in the fundus for the angiograms and $2500 \mu \mathrm{m}$ for the colour photographs, respectively. At study entry, the mean area occupied by drusen in the treatment group was not significantly $(p>0.5-0.7)$ different from that of the control group.
\end{abstract}

Results-The mean drusen area of the angiograms and fundus colour photographs in the treated group decreased significantly from $19 \cdot 3 \%$ to $13 \cdot 8 \%$ $(p=0.002)$ and from $7 \cdot 84 \%$ to $5 \cdot 02 \%$ $(p=0.005)$, respectively. In the untreated group, the mean area occupied by drusen increased significantly from $17 \cdot 4 \%$ to $20 \cdot 4 \%(p=0.030)$ and from $8.33 \%$ to $9.23 \%$ $(p=0.002)$, respectively. No significant changes in visual acuity $(p>0.05-0.5)$ or in visual fields $(p>0.05-0.3)$ occurred in either of the two groups during 6 months.

Conclusion-The study suggests that the area occupied by soft drusen in patients with early ARM decreases after perifoveal laser photocoagulation but increases in an untreated control group.

(Br f Ophthalmol 1995; 79: 905-909)

Age-related maculopathy (ARM) is the leading cause of visual loss among elderly people in
Western countries. ${ }^{1}$ ARM embraces a broad spectrum of retinal disorders and visual dysfunction, ranging from drusen and a mild decrease in visual acuity to the severe end stage, disciform degeneration. Risk factors for the development of exudative or atrophic maculopathy have previously been estimated in several studies. Patients with disciform degeneration in one eye who were followed over a period of 4-5 years were reported to face a $10-58 \%$ risk of developing neovascular lesions in the second eye..$^{2-4}$ Drusen size, drusen confluence, and focal hyperpigmentation were shown to be significant risk factors. ${ }^{45}$ Recently, Holz et al estimated the incidence of new lesions in patients with bilateral drusen and good visual acuity in a prospective study. ${ }^{5}$ In $13.5 \%$ of patients, new lesions occurred in one or both eyes, the patients being followed over a period of 3 years. The cumulative incidence of exudative or non-exudative lesions was $8.55 \%$ at 1 year, $16.37 \%$ at 2 years, and $23.52 \%$ at 3 years for patients older than 65 years of age. The Macular Photocoagulation Study Group has demonstrated that laser treatment of choroidal neovascular membranes secondary to ARM is beneficial in preventing or delaying large losses of visual acuity. ${ }^{6}$ Unfortunately, the great majority of patients with exudative maculopathy are untreatable. Recently Moisseiev et al showed that only $26 \%$ of patients with exudative ARM were eligible for laser photocoagulation therapy. ${ }^{7}$ In addition, 50\% recurred after laser therapy. As yet, there is no effective therapy for the geographically atrophic form of ARM. It therefore seems important to find new therapeutic modalities preventing exudative maculopathy. In 1991, Siegelman presented a case report on perifoveal laser photocoagulation of soft drusen maculopathy with favourable outcome. ${ }^{8}$ At the annual meeting of the American Academy of Ophthalmology in Chicago in 1993, Ruiz-Moreno et al reported on a study of direct perifoveal photocoagulation in 32 patients with soft drusen maculopathy. Visual acuity improved significantly without detectable alterations in the visual field. Recently, Figueroa et al presented results of a pilot study in which confluent soft drusen involving the fovea were treated with argon green laser. ${ }^{9}$ One laser spot was applied to each soft drusen in the temporal macula. Treated as well as untreated drusen disappeared within 10 months. We performed a 6 month prospective study comprising 20 patients with soft drusen maculopathy treated with argon laser photocoagulation over the drusen area and 19 age-matched controls. 
Table 1 Treatment group at study entry and at follow up

\begin{tabular}{|c|c|c|c|c|c|c|c|c|c|c|}
\hline & \multirow{3}{*}{$\begin{array}{l}\text { Age at } \\
\text { entry }\end{array}$} & \multirow[b]{3}{*}{ Sex } & \multicolumn{4}{|l|}{ Acuity } & \multicolumn{4}{|c|}{ Treated eye, drusen area } \\
\hline & & & \multicolumn{2}{|c|}{ Treated eye } & \multicolumn{2}{|l|}{ Fellow eye } & \multicolumn{2}{|c|}{ Colour photographs } & \multicolumn{2}{|c|}{ Angiograms } \\
\hline & & & Entry & Follow up & Entry & Follow up & Entry & Follow up & Entry & Follow up \\
\hline $\begin{array}{l}\text { Mean } \\
\text { SD }\end{array}$ & $\begin{array}{r}70 \cdot 2 \\
71 \cdot 3 \\
75 \cdot 6 \\
78 \cdot 3 \\
66 \cdot 6 \\
69 \cdot 3 \\
80 \cdot 0 \\
65 \cdot 5 \\
80 \cdot 4 \\
75 \cdot 5 \\
79 \cdot 6 \\
82 \cdot 3 \\
73 \cdot 0 \\
61 \cdot 8 \\
72 \cdot 2 \\
75 \cdot 9 \\
61 \cdot 5 \\
61 \cdot 8 \\
71 \cdot 1 \\
53 \cdot 2 \\
71 \cdot 3 \\
7 \cdot 7\end{array}$ & $\begin{array}{l}M \\
M \\
M \\
M \\
M \\
F \\
F \\
F \\
M \\
M \\
F \\
M \\
F \\
M \\
M \\
F \\
F \\
F \\
M \\
M\end{array}$ & $\begin{array}{l}1.0 \\
1.0 \\
1.0 \\
1.0 \\
1.0 \\
0.8 \\
0.8 \\
0.8 \\
0.8 \\
1.0 \\
0.9 \\
0.8 \\
0.9 \\
1.0 \\
1.0 \\
1.0 \\
1.0 \\
1.0 \\
0.9 \\
1.0 \\
0.94 \\
0.09\end{array}$ & $\begin{array}{l}1.0 \\
1.0 \\
1.0 \\
1.0 \\
1.0 \\
0.8 \\
0.8 \\
0.9 \\
0.8 \\
1.0 \\
0.7 \\
0.8 \\
1.0 \\
1.0 \\
0.8 \\
1.0 \\
1.0 \\
1.0 \\
1.0 \\
1.0 \\
0.93 \\
0.10\end{array}$ & $\begin{array}{l}\text { CF, discif ch } \\
1.0 \\
\text { CF, discif ch } \\
\mathrm{CF} \text {, discif ch } \\
1.0 \\
0.9 \\
0.6 \\
1.0 \\
0.5 \\
\mathrm{CF} \text {, discif ch } \\
\mathrm{CF} \text {, discif ch } \\
0.9 \\
0.8 \\
1.0 \\
\mathrm{CF} \text {, discif ch } \\
0 \cdot 7 \\
1.0 \\
1.0 \\
0.9 \\
\mathrm{CF} \text {, discif } \mathrm{ch}\end{array}$ & $\begin{array}{l}\text { CF, discif ch } \\
1 \cdot 0 \\
\text { CF, discif ch } \\
\text { CF, discif ch } \\
1.0 \\
0.9 \\
0.6 \\
1 \cdot 0 \\
0.5 \\
\text { CF, discif ch } \\
\mathrm{CF} \text {, discif ch } \\
0 \cdot 7 \\
0 \cdot 1 \\
1.0 \\
\mathrm{CF} \text {, discif ch } \\
0 \cdot 8 \\
1.0 \\
1.0 \\
0.9 \\
\mathrm{CF} \text {, discif } \mathrm{ch}\end{array}$ & $\begin{array}{r}10 \cdot 97 \\
5 \cdot 37 \\
4.99 \\
3 \cdot 89 \\
6 \cdot 79 \\
2 \cdot 81 \\
4 \cdot 13 \\
7 \cdot 74 \\
13 \cdot 27 \\
8 \cdot 33 \\
6 \cdot 67 \\
9 \cdot 08 \\
2.97 \\
1 \cdot 34 \\
18 \cdot 00 \\
8 \cdot 05 \\
10 \cdot 38 \\
3.96 \\
20 \cdot 77 \\
7 \cdot 23 \\
7.84 \\
4.99\end{array}$ & $\begin{array}{r}10.98 \\
5.34 \\
4.79 \\
2.20 \\
4.72 \\
3.85 \\
3.07 \\
5.31 \\
6.43 \\
3.87 \\
5.04 \\
6.04 \\
6.52 \\
1.29 \\
12.24 \\
3.46 \\
7.49 \\
0.40 \\
4.97 \\
2.40 \\
5.02 \\
2.89\end{array}$ & $\begin{array}{r}33 \cdot 73 \\
10 \cdot 49 \\
17 \cdot 50 \\
0.97 \\
17 \cdot 84 \\
28 \cdot 66 \\
15 \cdot 30 \\
29 \cdot 89 \\
27 \cdot 23 \\
17 \cdot 01 \\
10 \cdot 88 \\
28 \cdot 78 \\
14 \cdot 75 \\
13 \cdot 66 \\
36 \cdot 27 \\
12 \cdot 32 \\
13 \cdot 03 \\
2 \cdot 56 \\
34 \cdot 23 \\
20 \cdot 09 \\
19 \cdot 26 \\
10 \cdot 27\end{array}$ & $\begin{array}{r}32 \cdot 34 \\
8.74 \\
13.70 \\
1.09 \\
12.99 \\
14.78 \\
16.43 \\
15 \cdot 75 \\
22 \cdot 60 \\
10 \cdot 07 \\
7 \cdot 20 \\
24 \cdot 80 \\
6.11 \\
11 \cdot 10 \\
43.54 \\
8.07 \\
4.49 \\
1.24 \\
7.70 \\
12.76 \\
13.77 \\
10.42\end{array}$ \\
\hline
\end{tabular}

Discif $\mathrm{ch}=$ disciform changes; $\mathrm{CF}=$ counting fingers.

We were able to demonstrate a significant reduction in the total area of soft drusen.

\section{Materials and methods}

Thirty nine consecutive patients with soft drusen maculopathy and a visual acuity of 0.8 $(20 / 25)$ or better participated in this prospective study. The patients were randomised to perifoveal laser photocoagulation with argon green light over the drusen area (20 patients) or to a control group (19 patients). The treated group consisted of 12 men and eight women (Table 1). Seven of them had a disciform lesion in one eye. In those cases, the other eye was treated. Thirteen patients had soft drusen maculopathy in both eyes, with a difference in visual acuity of at most three Snellen lines. In three of these patients, visual acuity was below 0.8 in one eye, and therefore the better eye was treated. In the remaining 10 patients, the eyes were randomised to treatment or no treatment. Mean age was 71.3 (SD $7 \cdot 7$ ) years, range $53 \cdot 2-82 \cdot 3$ years. The control group consisted of four men and 15 women (Table 2). Seven of them had a disciform lesion in one eye, two suffered from vascular lesions in the optic nerve, and one had only light perception in the first eye because of encephalitic lesions from young age. In these cases, the better eye was treated. The remaining nine patients had soft drusen maculopathy in both eyes, with a difference in visual acuity of at most four Snellen lines. In three of these patients, visual acuity was below 0.8 in one eye, and therefore the better eye was followed. In the remaining six patients, the eyes were randomised to be included in the study or not. Mean age was $68.5(6 \cdot 2)$ years, range $57 \cdot 3-78.8$ years. There was no significant $(p>0.2)$ difference in age between the treatment group and the control group.

All patients were subjected to careful ophthalmic examination. The anterior segment of the eyes was normal. The ocular media were clear enough for a detailed evaluation of the fundus. Intraocular pressure (Goldmann applanation) was less than $22 \mathrm{~mm} \mathrm{Hg}$. The

Table 2 Control group at study entry and at follow up

\begin{tabular}{|c|c|c|c|c|c|c|c|c|c|c|}
\hline & \multirow{3}{*}{$\begin{array}{l}\text { Age at } \\
\text { entry }\end{array}$} & \multirow[b]{3}{*}{ Sex } & \multicolumn{4}{|l|}{ Acuity } & \multicolumn{4}{|c|}{ Control eye, drusen area } \\
\hline & & & \multicolumn{2}{|c|}{ Control eye } & \multicolumn{2}{|l|}{ Fellow eye } & \multicolumn{2}{|c|}{ Colour photographs } & \multicolumn{2}{|c|}{ Angiograms } \\
\hline & & & Entry & Follow up & Entry & Follow up & Entry & Follow up & Entry & Follow up \\
\hline $\begin{array}{l}\text { Mean } \\
\text { SD }\end{array}$ & $\begin{array}{r}72 \cdot 8 \\
64 \cdot 6 \\
73 \cdot 7 \\
68 \cdot 8 \\
69 \cdot 3 \\
57 \cdot 7 \\
78 \cdot 8 \\
70 \cdot 7 \\
59 \cdot 3 \\
69 \cdot 8 \\
66 \cdot 0 \\
65 \cdot 8 \\
63 \cdot 9 \\
57 \cdot 3 \\
67 \cdot 3 \\
72 \cdot 0 \\
68 \cdot 8 \\
75 \cdot 2 \\
78 \cdot 8 \\
68 \cdot 5 \\
6 \cdot 2\end{array}$ & $\begin{array}{l}F \\
F \\
F \\
F \\
F \\
M \\
F \\
F \\
F \\
F \\
F \\
F \\
F \\
M \\
F \\
F \\
M \\
F \\
M\end{array}$ & $\begin{array}{l}1.0 \\
0.7 \\
1.0 \\
1.0 \\
1.0 \\
1.0 \\
0.8 \\
0.8 \\
1.0 \\
1.0 \\
0.8 \\
1.0 \\
0.9 \\
1.0 \\
1.0 \\
1.0 \\
1.0 \\
1.0 \\
1.0 \\
0.95 \\
0.10\end{array}$ & $\begin{array}{l}1 \cdot 0 \\
0.6 \\
1.0 \\
1.0 \\
1.0 \\
1.0 \\
0.8 \\
0.9 \\
1 \cdot 0 \\
1.0 \\
0.7 \\
1 \cdot 0 \\
0.8 \\
1 \cdot 0 \\
0.9 \\
1 \cdot 0 \\
0.9 \\
1 \cdot 0 \\
1.0 \\
0.93 \\
0.12\end{array}$ & $\begin{array}{l}\text { HM, discif ch } \\
0 \cdot 5 \text {, discif ch } \\
\text { CF, discif } \mathrm{ch} \\
\mathrm{HM} \text {, discif } \mathrm{ch} \\
\mathrm{HM} \text {, discion } \\
1 \cdot 0 \\
\mathrm{P} \text {, enc lesion } \\
\mathrm{HM} \text {, discif ch } \\
1 \cdot 0 \\
0 \cdot 7 \\
1 \cdot 0 \\
\mathrm{CF} \text {, discif ch } \\
1 \cdot 0 \\
\mathrm{CF} \text {, discif ch } \\
1 \cdot 0 \\
0 \cdot 9 \\
\mathrm{HM} \text {, ON lesion } \\
\mathrm{CF} \text {, ON lesion } \\
0.6\end{array}$ & $\begin{array}{l}\text { HM, discif ch } \\
0 \cdot 5 \\
\mathrm{CF} \text {, discif } \mathrm{ch} \\
\mathrm{HM} \text {, discif } \mathrm{ch} \\
\mathrm{HM} \text {, discif ch } \\
1 \cdot 0 \\
\mathrm{P} \text {, enc lesion } \\
\mathrm{HM} \text {, discif ch } \\
1 \cdot 0 \\
0 \cdot 5 \\
0 \cdot 7 \\
\mathrm{CF} \text {, discif ch } \\
1 \cdot 0 \\
\mathrm{CF} \text {, discif ch } \\
0 \cdot 8 \\
0 \cdot 9 \\
\mathrm{HM} \text {, ON lesion } \\
\mathrm{CF} \text {, ON lesion } \\
0 \cdot 6\end{array}$ & $\begin{array}{r}2 \cdot 71 \\
18 \cdot 54 \\
5.98 \\
7.99 \\
2 \cdot 67 \\
4.95 \\
4.51 \\
10 \cdot 08 \\
5 \cdot 19 \\
8 \cdot 51 \\
13 \cdot 84 \\
8.90 \\
24 \cdot 48 \\
1.87 \\
5.55 \\
11.81 \\
8 \cdot 03 \\
9 \cdot 23 \\
3.36 \\
8.33 \\
5.73\end{array}$ & $\begin{array}{r}2 \cdot 73 \\
19.88 \\
6.21 \\
8.01 \\
2.78 \\
6.98 \\
5.71 \\
13.28 \\
6.98 \\
9 \cdot 08 \\
13.48 \\
9.85 \\
26.56 \\
3.14 \\
5.08 \\
14.05 \\
7.32 \\
10 \cdot 22 \\
3.94 \\
9.23 \\
6.12\end{array}$ & $\begin{array}{r}14 \cdot 85 \\
27.09 \\
16.46 \\
28.23 \\
5 \cdot 17 \\
14.52 \\
11.09 \\
25.97 \\
17 \cdot 65 \\
25 \cdot 84 \\
17 \cdot 82 \\
28 \cdot 68 \\
14 \cdot 21 \\
14.56 \\
17.56 \\
11.31 \\
17.61 \\
12.96 \\
9 \cdot 20 \\
17.41 \\
6.79\end{array}$ & $\begin{array}{r}13 \cdot 04 \\
24 \cdot 11 \\
21 \cdot 60 \\
37 \cdot 44 \\
13 \cdot 27 \\
19 \cdot 38 \\
10 \cdot 27 \\
31 \cdot 74 \\
15 \cdot 11 \\
30 \cdot 87 \\
33 \cdot 44 \\
32 \cdot 62 \\
20 \cdot 67 \\
14 \cdot 71 \\
17 \cdot 09 \\
6 \cdot 08 \\
18 \cdot 18 \\
20 \cdot 53 \\
7.93 \\
20 \cdot 42 \\
9 \cdot 15\end{array}$ \\
\hline
\end{tabular}

Discif $\mathrm{ch}=$ disciform changes; enc lesion=state post encephalitic lesion; $\mathrm{ON}$ lesion=state post vascular lesion in the optic nerve; $\mathrm{HM}=$ hand movements; $\mathbf{C F}=$ counting fingers; $\mathbf{P}=$ light perception. 
optic disc was normal. The eyes included in the study showed soft drusen, some of them confluent, and mild pigmentary changes without clumping but no pigment epithelium detachment, no subretinal neovascularisation or haemorrhage, and no macular atrophy.

Follow up visits were scheduled for all patients at 1,3, and 6 months after enrolment. At each scheduled follow up visit, the patient was examined for best corrected visual acuity, colour vision, central visual field, colour contrast sensitivity, and fundus condition.

Refraction was performed in a standardised fashion, initially and at each follow up, and distance visual acuity was tested at a distance of 5 metres, using a GP (Snellen) letter chart (Preisler, Malmö, Sweden).

The $10^{\circ}$ central visual field was evaluated using the Humphrey field analyser 640 (Carl Zeiss AB, Stockholm, Sweden), 10-2 threshold test with a size III white test spot. Mean threshold value for the visual fields at baseline was compared with that at the 6 month follow up. In order to obtain a mean value, the printout value in decibels (dB) (logarithmic scale) was first converted into Apostilb (Asb) (linear scale).

The standard Farnsworth panel D-15 (Vitactive, Stockholm, Sweden) was used to detect acquired losses of hue discrimination.

Colour contrast sensitivity along the protan, deutan, and tritan colour confusion lines was measured by a system ${ }^{10-12}$ and a procedure ${ }^{12}$ earlier described by Arden et al, the differences being that the colours were displayed on a NEC Multi Sync 6 FG monitor with a dot pitch of $0.28 \mathrm{~mm}$, that we used a $25 \mathrm{MHz}$ Intel 80386 DX computer with an 80387 Math Coprocessor and that the graphics card was a TSL 206 card with 24 bit palette. At the resolution we used, $960 \times 760$ pixels, this card has a refresh rate of $90 \mathrm{~Hz}$.

For threshold measurements in normals, an age-matched control group (mean age $67 \cdot 7$ $(6 \cdot 5)$ years) was used (manuscript submitted).

Standard fundus $50^{\circ}$ colour photographs using a Nikon fundus camera NF-505 (Bergströms Instrument, Stockholm, Sweden) were obtained when the patients entered the study and then every 3 months.

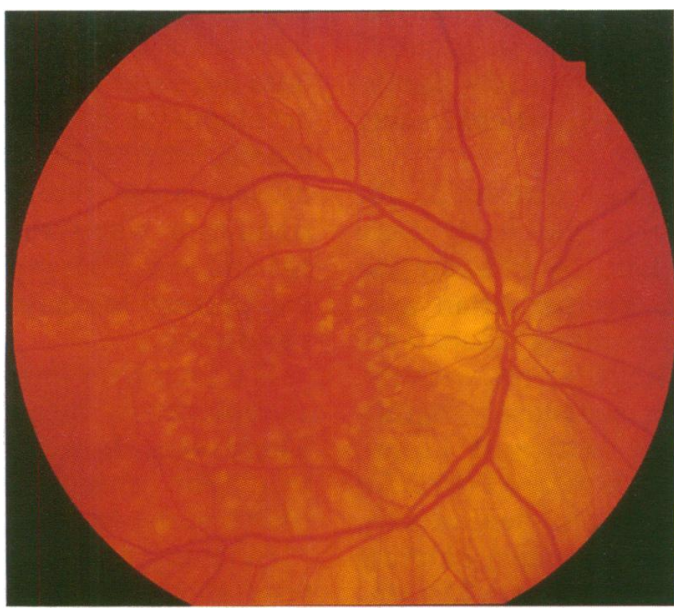

Figure 1 A photograph taken immediately after laser treatment to show the mild, greyish laser spots.
Fluorescein angiography was performed at study entry and then repeated every 3 months. Laser photocoagulation was performed using argon green light (Lasertek $41 \mathrm{AK}$, Martinsson \& Co Instrument $\mathrm{AB}$, Hägersten, Sweden). Mild laser burns, 51-154 spots of $200 \mu \mathrm{m}$ at $0 \cdot 1-0.2 \mathrm{~W}$ for 0.05 seconds, producing a greyish reaction (Fig 1), were placed within a temporal horseshoe-shaped area extending from a distance no less than $500 \mu \mathrm{m}$ from the centre of the fovea to the vascular arcades. The laser burns were placed on the drusen and scattered over areas where no drusen were present.

When estimating the area of drusen we had access to magnified photographs, colour fundus photographs with a size of $20 \times 30 \mathrm{~cm}$, and fluorescein angiograms measuring $18 \times 24 \mathrm{~cm}$. The photographs and angiograms were covered with a clear plastic sheet on which all drusen within a certain area were outlined and the drusen area filled in. The area was a circle concentric with the centre of the macula and with a radius corresponding to $1250 \mu \mathrm{m}$ in the fundus of an average eye for the angiograms and $2500 \mu \mathrm{m}$ for the fundus colour photographs (Figs 2A, B). The fundus photographs as well as the angiograms were handled at random as they were returned by the photographer, and never in pairs (prepost). To test method reliability, the formula for 'the standard deviation of a single determination' was used. The reliability was found to be good, this standard deviation being $0 \cdot 60$. Using a Dextra DF 1200 scanner, the pattern of painted drusen of the plastic sheet was then scanned into a computer and the area calculated by a program in DOS, graphic mode. The area of the drusen was determined as a portion of the total area of the circle - that is, the number of pixels covering the drusen area, and the pixels of the entire area of the circle were counted and the ratio calculated.

Informed consent was obtained from all subjects and the study was approved by the ethics committee of the University of Linköping.

Statistical analyses were carried out using Student's $t$ test for comparing the treated group with the untreated group and the paired $t$ test for comparisons within the two groups. In addition, to adjust for the effect of any difference in mean age or sex distribution when comparing the treatment groups, analysis of covariance was used. ${ }^{13}$ In order to determine the $\mathrm{p}$ value, the double sided test was used.

\section{Results}

Mean visual acuity for the treated group when entering the study was $0.94(0.09)$ and after 6 months was $0.93(0 \cdot 10)$. These figures are not significantly different $(p>0.5)$. For the untreated group, the corresponding figures were $0.95(0.10)$ and $0.93(0.12)$, respectively. There is no significant difference between these two figures $(p>0 \cdot 05)$.

Mean threshold value for the visual fields in the treated group was $28.36 \mathrm{~dB}$ at baseline and $28.97 \mathrm{~dB}$ after 6 months $(\mathrm{p}>0.05)$. In the 


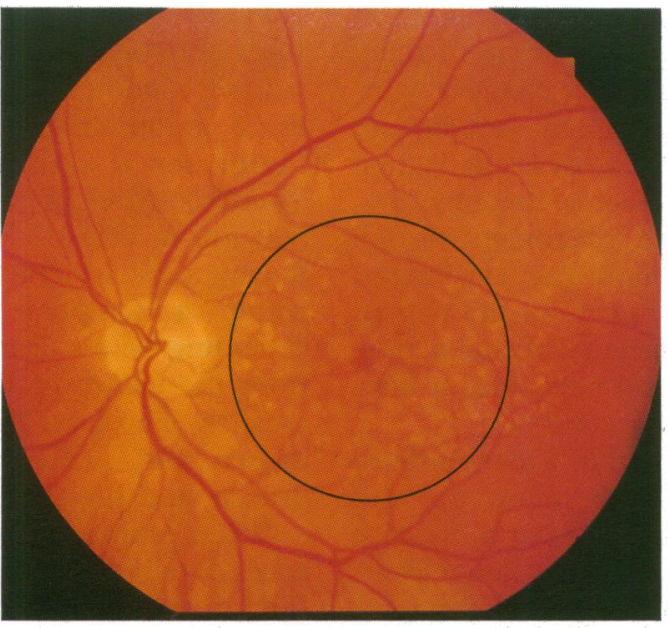

Fig $2 A$

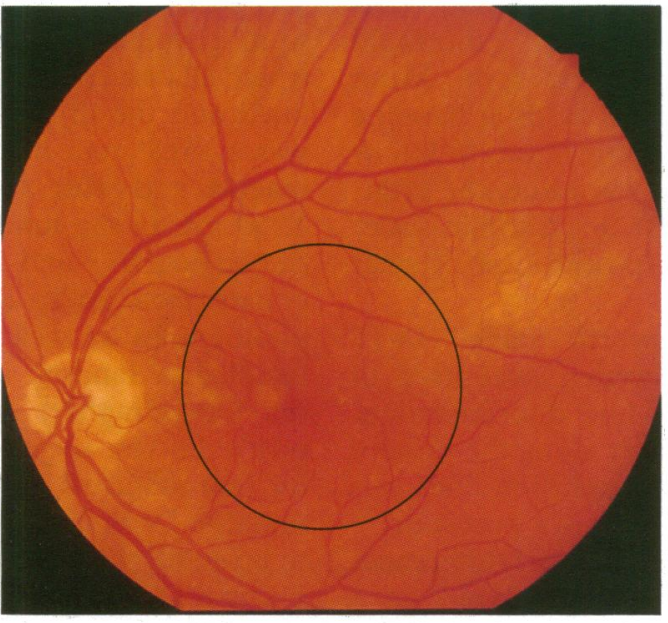

Fig 2B

Figure 2 Colour fundus photographs of a 71-year-old male patient with soft drusen maculopathy before $(A)$ and 6 months after argon (green) laser treatment (B). Note the reduction in total drusen area. Regression of drusen is least prominent nasally to the fovea - that is, in the area furthest away from the laser burns. The radius of the circle corresponds to $2500 \mu \mathrm{m}$ in the fundus.

untreated control group, the mean threshold values were $28.28 \mathrm{~dB}$ and $25.16 \mathrm{~dB}$, respectively $(\mathrm{p}>0 \cdot 3)$.

Six patients failed the D-15 test in the treated group and five in the untreated group when entering the study, all but one in both groups making mistakes along the blue-yellow axis. At 6 months, the corresponding numbers were six and four, respectively. No protan-like or deutan-like defects were found in either of the groups. There was no statistically significant difference within the two groups, using the $\chi^{2}$ analysis.

The mean colour contrast thresholds for treated patients at entry to the study were $12.36 \%$ for the protan axis, $14.72 \%$ for the deutan axis, and $27.59 \%$ for the tritan axis. After 6 months, the corresponding values were $14.96 \%, 15.01 \%$, and $30 \cdot 26 \%$, respectively. These differences are not statistically significant $(p>0 \cdot 1-0 \cdot 8)$. For the untreated group, the colour contrast thresholds were $11.44 \%$ for the protan axis, $13.00 \%$ for the deutan axis, and $19.50 \%$ for the tritan axis when entering the study and $12.25 \%, 12.06 \%$, and $22.71 \%$, respectively, after 6 months. The differences are not statistically significant $(p>0 \cdot 2-0 \cdot 4)$.
Marked interindividual variations were found, particularly regarding the tritan axis. These mean values are all elevated compared with those of normals which, according to Arden et $a l$, are found between 4.5 and $7.7 \%$ for the protan, deutan, and tritan axes. ${ }^{1014}$ In our agematched control group of normals, however, we found the threshold for the tritan axis to be $10.6 \%$ - that is, higher than in the Arden material. Nevertheless, the mean values of our patients were significantly $(p<0.01-0.001)$ elevated.

The mean drusen area in the angiograms in the treated group decreased significantly $(p=0.002)$ from $19.3 \%$ of the total area of a circle with a radius corresponding to $1250 \mu \mathrm{m}$ in the fundus to $13.8 \%$ after 6 months. The mean drusen area in the colour fundus photographs also decreased significantly from $7 \cdot 84 \%$ to $5.02 \%$ after 6 months $(p=0.005)$ (Figs $2 A$, $B)$. In the untreated group, the mean drusen area in the angiograms and the colour fundus photographs increased significantly during the 6 month period. In the angiograms, the area increased from $17 \cdot 4 \%$ to $20 \cdot 4 \% \quad(p=0.030)$ and in the fundus photographs from $8.33 \%$ to $9 \cdot 23 \%(p=0 \cdot 002)$. Adjustments for age and sex gave essentially the same results, and the differences in the mean 6 month change of the drusen area remained clearly statistically significant $(p<0.001$ for the angiograms; $p=0.013$ for the fundus photographs).

\section{Discussion}

In spite of the fact that selection for treatment or no treatment was performed in a totally randomised fashion, there was an imbalance regarding sex with more men in the treatment group and more women in the control group. Whereas Klein et al reported that the prevalence of early ARM (including soft drusen) in the USA was higher for women than for men, ${ }^{15}$ no such difference was found by Vingerling et $a l^{16}$ or in the Beaver Dam eye study. ${ }^{17}$ On the other hand, this latter study as well as Maltzman et al ${ }^{18}$ found that exudative macular degeneration was more frequent in women compared with men. The Framingham study ${ }^{19}$ initially also reported a sex difference. In a later analysis of the Framingham material, ${ }^{20}$ no such difference was found, however. Importantly, most reports indicate that sex does not seem to be a risk factor with respect to development of neovascular and/or atrophic lesions. ${ }^{1621-25}$ In our study, the change in the drusen area remained clearly statistically significant when adjustments were made for age and sex. Therefore, the imbalance in sex of the present investigation seems to be of no significance.

We found no improvement in visual acuity as reported by Siegelman and Ruiz-Moreno. ${ }^{8}$ There was, however, no visual loss before treatment, mean visual acuity being 0.94 $(0.09)$ in the treated group.

At study entry, colour contrast sensitivity tests showed a deterioration in colour discrimination for all three colour axes, indicating an impairment in retinal function. This is in 
accordance with our previous findings that colour contrast sensitivity is significantly lower in patients with early ARM compared with age-matched normals (manuscript submitted).

After laser treatment, the area occupied by drusen decreased significantly. The mechanism is unknown but could involve Bruch's membrane, the retinal pigment epithelium, and/or the photoreceptors. Previous studies showed that laser photocoagulation triggers proliferation of the pigment epithelial cells. With mild and moderate burns, the epithelium reforms as a single layer of cells which become polarised with apical villi and basement membrane systems. ${ }^{2627}$ It is possible that such a proliferating retinal pigment epithelium may be capable of phagocytising drusen material. Perifoveal laser photocoagulation of soft drusen, the latter constituting a considerable risk of development of disciform lesions, may offer a promising prophylactic treatment of ARM. However, the reduction in drusen area obtained does not automatically guarantee a reduced risk of development of exudative and neovascular lesions. This can be proved only by a long term follow up of treated patients. Consequently a more extensive patient group will be followed up during a longer period of time in order to elucidate this issue further.

The present study was supported by grants from the Swedish (We thank medical student Martin Frennesson for skilful assistance with the computer analyses.

1 Leibowitz HM, Kreuger DE, Maunder LR. The Framingham Eye Study Monograph. Surv Ophthalmol 1980; 24: 335-607.

2 Gass JDM. Drusen and disciform macular detachment and degeneration. Arch Ophthalmol 1973; 90: 206-17.

3 Gregor Z, Bird AC, Chisholm IH. Senile disciform macular degeneration in the second eye. Br $\mathcal{F}$ Ophthalmol 1977; 61: 141-7.

4 Bressler SB, Maguire MG, Bressler NM, Fine SL, the Macular Photocoagulation Study Group. Relationship of drusen and abnormalities of the retinal pigment epithelium to the prognosis of neovascular macular degeneralium to the prognosis of neovascular macil
tion. Arch Ophthalmol 1990; 108: 1442-7.

5 Holz FG, Wolfensberger TJ, Piguet B, Gross-Jendroska M, Wells JA, Minassian DC, et al. Bilateral macular drusen in age-related macular degeneration. Ophthalmology 1994; 101: $1522-8$.

6 Macular Photocoagulation Study Group. Argon laser photocoagulation of neovascular maculopathy. Five-year results from randomized clinical trials. Arch Ophthalmol 1991; 109: 1109-14

7 Moisseiev J, Alhalel A, Masuri R, Treister G. The impact of the Macular Photocoagulation Study results on the treatment of exudative age-related macular degeneration. Arch Ophthalmol 1995; 113: 185-9.

8 Siegelman J. Foveal drusen resorption one year after perifoveal laser photocoagulation. Ophthalmology 1991; 98: 1379-83.

9 Figueroa MS, Regueras A, Bertrand J. Laser photocoagulation to treat macular soft drusen in age-related macular degeneration. Retina 1994; 14: 391-6.

10 Arden GB, Gündüz $\mathrm{K}$, Perry $\mathrm{S}$. Color vision testing with a computer graphics system. Clin Vis Sci 1988; 2 303-20.

11 Arden GB, Gündüz K, Perry S. Color vision testing with a computer graphics system: preliminary results. Doc Computer graphics system:

12 Arden GB, Berninger T, Hogg C, Perry S. A survey of color discrimination in German ophthalmologists. Changes associated with the use of lasers and operating microscopes. Ophthalmology 1991; 98: 567-75.

13 Armitage $P$, Berry G. Statistical methods in medical research. Oxford: Blackwell, 1987.

14 Berninger T, Canning C, Gündüz K, Strong N, Arden GB Using argon laser blue light reduces ophthalmologists' color contrast sensitivity. Argon blue and surgeons' vision. Arch Ophthalmol 1989; 107: 1453-8.

15 Klein R, Rowland ML, Harris MI. Racial/ethnic differences in age-related maculopathy. Third national health and nutrition examination survey. Ophthalmology 1995; 102: nutrition

16 Vingerling JR, Dielemans I, Hofman A, Grobbe DE, Hijmering M, Kramer CFL, et al. The prevalence of agerelated maculopathy in the Rotterdam study. Ophthalmology 1995; 102: 205-10.

17 Klein R, Klein BEK, Linton KLP. Prevalence of age-related maculopathy. The Beaver Dam Eye Study. Ophthalmology 1992; 99: 933-43.

18 Maltzman BA, Mulvihill MN, Greenbaum A. Senile macular degeneration and risk factors: a case-control macular degeneration and risk factors: a
study. Ann Ophthalmol 1979; 11: 1197-201.

19 Kahn AH, Leibowitz HM, Ganley JP, Kini MM, Colton T, Nickerson RS, et al. The Framingham eye study. 1 . Outline and major prevalence findings. Am $\mathcal{F}$ Epidemiol 1977; 106: 17-32.

20 Sperduto RD, Hiller R. Systemic hypertension and age-related maculopathy in the Framingham study. Arch Ophthalmol 1986; 104: 216-9.

21 Klein BE, Klein R. Cataracts and macular degeneration in older Americans. Arch Ophthalmol 1982; 100: 571-3.

22 Smiddy WE, Fine SL. Prognosis of patients with bilateral macular drusen. Ophthalmology 1984; 91: 271-7.

23 Bressler NM, Bressler SB, Seddon JM, Gragoudas ES, Jacobson L. Drusen characteristics in patients with exudative versus non-exudative age-related macular degeneration. Retina 1988; 8: 109-14.

24 Mitchell P, Smith W, Attebo $\mathrm{K}$. The prevalence of agerelated maculopathy: results from the Blue Mountains eye study. Invest Ophthalmol Vis Sci 1995; 36 (No 4, suppl): 1931 .

25 Stock CJ, Canter LA, Puklin JE, Frank RN. Gender, race, iris color, and age-related macular degeneration. Invest Ophthalmol Vis Sci 1995; 36 (No 4, suppl): 42.

26 Marshall J. Interactions between sensory cells, glial cells and the retinal pigment epithelium and their response to photocoagulation. Dev Ophthalmol 1981; 2: 308-17.

27 Miller H, Miller B, Ryan SJ. The role of retinal pigmen epithelium in the involution of subretinal neovascularization. Invest Ophthalmol Vis Sci 1986; 27: 1644-52. 